\title{
Radiographic Diagnosis of Simulated External Root Resorption in Multi-Rooted Teeth: The Influence of Spatial Resolution
}

\author{
Mariane F. L. S. Lacerda', Rafael B. Junqueira', \\ Thaísa M. G. Lima', Carolina O. Lima², \\ Caroline F. M. Girelli ${ }^{3}$, Francielle S. Verner' \\ ' Universidade Federal de Juiz de Fora, Departamento de Odontologia, \\ Campus GV, Governador Valadares, Minas Gerais, Brasil. \\ 2 Universidade Estadual do Rio de Janeiro, Departamento de Endodontia, \\ Rio de Janeiro, Brasil. \\ ${ }^{3}$ Associação Brasileira de Odontologia, Governador Valadares, \\ Minas Gerais, Brasil.
}

\begin{abstract}
The aim of this study was to evaluate the influence of spatial resolution (line pairs per millimetre - lp/ $\mathrm{mm}$ ) on the diagnosis of simulated external root resorption (ERR) in multi-rooted teeth by using digital periapical radiography. Forty human mandibular molars (80 roots) were used. The roots were divided into the following groups $(n=10)$ : control without root filling (WORF), control with root filling (WRF), small ERR$W O R F$, small ERR-WRF, moderate ERR-WORF, moderate ERR-WRF, extensive ERR-WORF and extensive ERR-WRF. Four digital radiographs (phosphor storage plates - PSP system) were taken of each tooth in three angulations. The PSPS were scanned with 10, 20, 25 and $40 \mathrm{lp} / \mathrm{mm}$. All images were assessed by three endodontists who used a five-point scale for presence and absence of ERR and classified its location (cervical, middle or apical third). ROC curves and one-way
\end{abstract}

ANOVA were performed $(p<0.01)$. Diagnosis of ERR in nonroot-filled teeth showed higher values of sensitivity for 20 $\mathrm{lp} / \mathrm{mm}$ and higher values of both specificity and accuracy for $40 \mathrm{lp} / \mathrm{mm}$. In root-filled teeth, sensitivity and accuracy were higher for $25 \mathrm{lp} / \mathrm{mm}$ and spatial resolution had no influence on specificity. The best resolution for diagnosis of small and extensive ERR was $25 \mathrm{lp} / \mathrm{mm}$, whereas for moderate ERR, it was $40 \mathrm{lp} / \mathrm{mm}$. Cervical ERR was the most difficult to diagnose, regardless of the spatial resolution. Higher spatial resolutions have improved the radiographic diagnosis of simulated ERR in multi-rooted teeth and this should be considered when performing digital radiographs.

Received: December 2019; Accepted: January 2020.

Keywords: digital dental radiography, root resorption, diagnostic imaging, endodontics.

\section{Diagnóstico radiográfico de reabsorção externa simulada em dentes multiradiculares: influência da resolução especial}

\begin{abstract}
RESUMO
O objetivo deste estudo foi avaliar a influência do número de pares de linhas em radiografia intra-oral digital, na precisão da detecção de reabsorção radicular externa. Quarenta molares inferiores ( $n=80$ raizes) foram submetidos ao preparo químico mecânico e em então, metade da amostra foi obturada. Em seguida, as raizes dos dentes foram aleatoriamente divididas de acordo com o tamanho da reabsorção radicular a ser simulada e com a presença e ausência de tratamento endodôntico. As RRE foram realizadas com brocas esféricas diamantadas de tamanhos 1/2, 1, 2. Executou-se radiografias digitais por meio do sistema de aquisição semidireto com a utilização de placas de fósforo fotoestimuladas (PSP). Em cada dente, incidências orto, mésio e distorradial foram repetidas quatro vezes, para que pudessem ser digitalizadas com resoluções de 10,20,25, $40 \mathrm{pl} / \mathrm{mm}$. Após análise, verificou-se
\end{abstract}

que dentes obturados apresentaram menores valores de sensibilidade com 10, 20 e $25 \mathrm{pl} / \mathrm{mm}$ e maiores valores de especificidade e acurácia para as mesmas resoluções. Dentes sem obturação registraram maiores valores de sensibilidade para resolução 20 e menor para 40; no entanto, a especificidade e a acurácia, foram maiores com 40 e menores em 10. Em $R R E$ pequena, as resoluções 10 e $25 \mathrm{pl} / \mathrm{mm}$ foram respectivamente menos e mais acuradas; RRE média, foi maior com $40 \mathrm{pl} / \mathrm{mm}$ e RRE grandes foram melhores identificadas com 25. Correlacionando acertos no diagnóstico com localização das $R R E$, verificou-se que o terço cervical apresentou-se menos detectável. Concluiu-se que resolução espacial influenciou a detecção de RRE simuladas em radiografias periapicais digitais.

Palavras-chave: radiografia dentária digital, reabsorção da raiz, diagnóstico por imagem, endodontia. 


\section{INTRODUCTION}

External root resorption (ERR) is defined as the loss of dental mineral tissue, such as cement and dentine, as result of various factors (pathological or physiological) predisposing to alterations in osteoclast activity. Some of these factors are periapical lesions, orthodontic movements, tooth re-implantation, trauma, pressure from adjacent erupting teeth, and odontogenic and nonodontogenic cysts and tumours ${ }^{1,2}$. In general, ERR presents no clinical signal or symptom and is largely detected by means of routine radiographic examinations, being characterised by reduced root length or root surface defects. However, in most cases, these lesions are only diagnosed at an advanced stage, thus compromising the treatment itself $^{3,}{ }^{4}$. Early diagnosis is therefore key to preserving the teeth involved, which makes radiographic detection of ERR very important for the dental surgeon ${ }^{5}$.

Digital radiographic systems have recently replaced radiographic films, as they emit lower radiation levels, use no chemical process, reduce work time, facilitate image acquisition/storage and enable image re-use, in addition to improving both practitioner-patient visual communication and the image itself $f^{4,6,7}$.

Phosphor storage plates (PSP) are a type of digital image receptor commonly used intra-orally, which resemble conventional periapical films in size and thickness. The choice of the ideal system depends on factors related to the digital image which can directly influence image resolution and quality. Among these factors, we can highlight spatial resolution, which is directly related to the number of line pairs per millimetre $(\mathrm{lp} / \mathrm{mm})$ in the digital receptors. According to the manufacturers, the higher the number of $1 \mathrm{p} / \mathrm{mm}$, the better the image resolution ${ }^{8}$.

To date, studies assessing the influence of the number of $1 \mathrm{p} / \mathrm{mm}$ on the diagnostic accuracy of radiography have been limited to the diagnosis of root fractures ${ }^{7,9}$ and caries lesions ${ }^{10}$.

Considering that it is challenging to diagnose ERR correctly on periapical radiographs, especially in multi-rooted teeth, we can highlight the importance of performing studies to investigate digital system resources in order to improve the diagnosis of this endodontic complication. Thus, the aim of the present study was to assess the influence of spatial resolution on the diagnosis of simulated ERR in multi-rooted teeth by using digital periapical radiography. The null hypothesis to be tested was that spatial resolution does not influence the diagnosis of ERR.

\section{MATERIALS AND METHODS}

This research was approved by the Human Research Ethics Committee by protocol number 1.998.579/2017. It followed the recommendations of the National Health Council of the Ministry of Health for research in human subjects.

\section{Sample Selection and Preparation}

Forty newly-extracted lower molars ( $\mathrm{n}=80$ roots) were selected for reasons not inherent to the study and stored in formalin solution $10 \%$ at a temperature of $6^{\circ} \mathrm{C}$. The teeth were clinically and radiographically inspected for further selection. Two-rooted lower molars with healthy roots were included, whereas those teeth with incomplete root formation, fused roots, supernumerary roots, obliterated root canals, root resorption (external or internal), fractured file inside the root canal, intraradicular posts and pulp calcifications or which had been endodontically treated were excluded. Teeth with cracks and root fractures, which were confirmed by using trans-illumination technique with high-power LED at $1200 \mathrm{~mW} / \mathrm{cm}^{2}$ (Radii Cal, SDI, Victoria, Australia), were also excluded,

In order to eliminate the identification of each tooth by the examiners, all crowns were sectioned at the cementoenamel junction with a double-sided steel disc (\#6702, Fava, São Paulo, Brazil) attached to a micro-motor (Beltec LB100, Araraquara, SP, Brazil).

The sample of roots was randomly divided into two groups, one $(n=40)$ without endodontic treatment (WORF) and other $(\mathrm{n}=40)$ with endodontic treatment (WRF), which was performed in appropriate laboratory by a single endodontic specialist. Working length (WL) was determined 1 $\mathrm{mm}$ beyond the apical foramen by using a \#'10 Kfile (Dentsply/Maillefer, Ballaigues, Switzerland). Roots were instrumented with Protaper system by using files SX, S1, S2, F1 and F2 (Dentsply/ Maillefer, Ballaigues, Switzerland), with the four latter being used until the WL was reached. A 2.5\% sodium hypochlorite solution was used for irrigation of the root canals, which were then dried with absorbent paper points F2 (Protaper Point- 
Maillefer, Dentsply) before being filled with the Tagger's hybrid technique using gutta-percha F2 (Dentsply/Maillefer, Ballaigues, Switzerland) and endodontic cement (Endofill, Dentsply/Maillefer, Petropolis, RJ, Brazil).

The roots were randomly divided into experimental groups for simulations of ERR, which were performed by using spherical diamond burs sizes 1/2, 1 and 2 (KG Sorensen, Cotia, São Paulo, Brazil) to create small $(n=20)$, moderate $(n=20)$ and extensive $(\mathrm{n}=20)$ defects, respectively. The burs were mounted on a high-speed motor (Kavo, Joinville, Brazil), positioned, and placed perpendicularly on the root surface to simulate ERRs with symmetrical depths. Each molar root received only one defect on its surface, with location (i.e. cervical, middle or apical third and buccal, lingual or distal face) defined randomly by using Excel 16.0 software (Office 2016, Microsoft Corporation, USA). Each group had the same amount of mesial and distal roots and the same number of ERR on radicular thirds.

Experimental groups were defined as follows: control without root filling (WORF) $(\mathrm{n}=10)$, control with root filling (WRF) $(\mathrm{n}=10)$, small ERR-WORF $(\mathrm{n}=10)$, small ERR-WRF $(\mathrm{n}=10)$, moderate ERR-WORF $(\mathrm{n}=10)$, moderate ERRWRF $(n=10)$, extensive ERR-WORF $(n=10)$ and extensive ERR-WRF $(\mathrm{n}=10)$.

In order to simulate the radiographic appearance of the periodontal ligament of the tooth within the alveolus, the entire root was covered with specific plastic wax (Plástica- Kotaimp Art's, São Paulo, SP, Brazil), resulting in a layer $0.3 \mathrm{~mm}$ thick. Thickness was confirmed using a digital calliper (Starrett ${ }^{\circledR}$ 799A, Starret, Itu, SP, Brazil). The teeth were placed individually and randomly into the residual alveoli of a macerated mandible.

\section{Image Acquisition}

Digital radiographs were taken by means of a semidirect digital imaging system with the use of photostimulable phosphor plates (PSP) (Vista Scan ${ }^{\circledR}$ (Dürr Dental, Beitigheim-Bissingen, Germany). Kilo-voltage peak $(\mathrm{kVp})$ and milliamperage $(\mathrm{mA})$ were the acquisition parameters set according to the characteristics of the equipment (Gendex Dental Systems, Lake Zurich, IL, USA), namely, $70 \mathrm{kVp}$ and $7 \mathrm{~mA}$. Exposure time of 0.10 seconds $(32.7$ $\mathrm{mGy} \cdot \mathrm{com}^{2}$ ) was determined for diagnosis after images with ideal contrast and density were obtained in pilot studies. This exposure time was used throughout the study. The distance between focus and PSP was standardised at $40 \mathrm{~cm}$ and followed the technique of parallelism by using an acrylic apparatus specially developed for periapical radiographs in vitro and soft tissue simulation. All images were obtained at ortho, mesial and distal angulations, ranging by $15^{\circ}$ in relation to the horizontal angulation. The angulations were repeated four times in each tooth so that the PSPs could be digitalised with a scanner (VistaScan Mini View ${ }^{\circledR}$, Dürr Dental, Bietigheim-Bissingen, Germany) at different resolutions of line pairs per millimetre: 10 1p/mm (500 dpi), 20 lp/mm (1000 dpi), 25 lp/mm (1270 dpi) and 40 lp/mm (2000 dpi).

\section{Image Evaluation}

After obtaining 480 radiographs, the images digitalised with different line pairs per millimetre were randomised in order to improve assessment reliability. The images were assessed by three endodontic specialists who were previously instructed regarding the assessments and blinded to the study's methodology. They examined the images individually for presence or absence of ERR in each root according to a 5-point scale, namely: 1 totally absent; 2 - probably absent; 3 - uncertain; 4 - probably present; and 5 - totally present. For cases in which the examiners considered presence of ERR (scores 4 and 5), it was further rated according to its location in the root thirds, i.e., cervical, middle or apical. Any discordant cases were jointly re-assessed by all three examiners so that agreement was achieved between at least two of them, thereby enabling the calculation of the response mode.

Periapical radiographs were assessed on Windows ${ }^{\circledR}$ photo viewer before being exported to .TIFF file format (uncompressed) by using the system's image acquisition software (DBS Win, Dürr Dental, Bietigheim-Bissingen, Germany). All assessments were performed on a 24-inch LCD monitor (MDRC 2124 (Barco Inc. Duluth, GA, USA) under ideal light conditions. Zoom, brightness and contrast tools could be used to improve the images.

After 30 days, a period considered to be long enough for the examiners to forget the images, $20 \%$ of the sample was re-assessed in order to calculate intra- and inter-rater reliability ${ }^{11}$. 


\section{Statistical Analysis}

Statistical analysis was carried out using the SPSS statistics software version 21.0 (IBM Corp, Armonk, New York, USA) at a significance level of $1 \%$. Weighted kappa test was used for intra- and inter-rater reproducibility. For comparison of the results of the images obtained at different resolutions $(1 \mathrm{p} / \mathrm{mm})$ with the gold standard, ROC (receiver operating characteristics) curves were built to determine the values of sensitivity, specificity and areas under ROC curve (accuracy). One-way analysis of variance (ANOVA) and post-hoc Tukey's test were used to compare the area values.

\section{RESULTS}

Kappa test showed that values for intra- and interrater reliability ranged from significant to almost perfect agreement ${ }^{12}$ ( 0.66 to 0.81 and 0.77 to 0.86 ), respectively.

ROC curves were calculated for each spatial resolution in the WORF and WRF groups. The values of sensitivity, specificity and areas under the ROC curves are shown in Table 1.
Analysis of diagnostic tests showed that spatial resolution and presence of root filling material significantly influenced the detection of simulated external root resorptions on digital periapical radiographs. Fig. 1 shows periapical radiographs of mandibular molars with and without endodontic treatment and presence of simulated RRE in different thirds of root canal.

By comparing the values of sensitivity, specificity and accuracy between the WORF and WRF groups regarding the different spatial resolutions, it was observed that root-filled teeth had lower values of sensitivity at resolutions of 10,20 and $25 \mathrm{lp} / \mathrm{mm}$ $(P<0.001)$ and higher values of specificity and accuracy at the same resolutions $(P<0.001)$. On the other hand, by comparing the values of sensitivity, specificity and accuracy obtained at each spatial resolution, it was found that the WORF group presented higher values of sensitivity at a resolution of $20 \mathrm{lp} / \mathrm{mm}(0.917)$ and lower values at $40 \mathrm{lp} / \mathrm{mm}$ (0.611). Moreover, non-root-filled teeth had higher values of specificity and accuracy at a resolution of $40 \mathrm{lp} / \mathrm{mm}$, respectively 1.00 and 0.873 , and lower values at $10 \mathrm{lp} / \mathrm{mm}$, respectively,
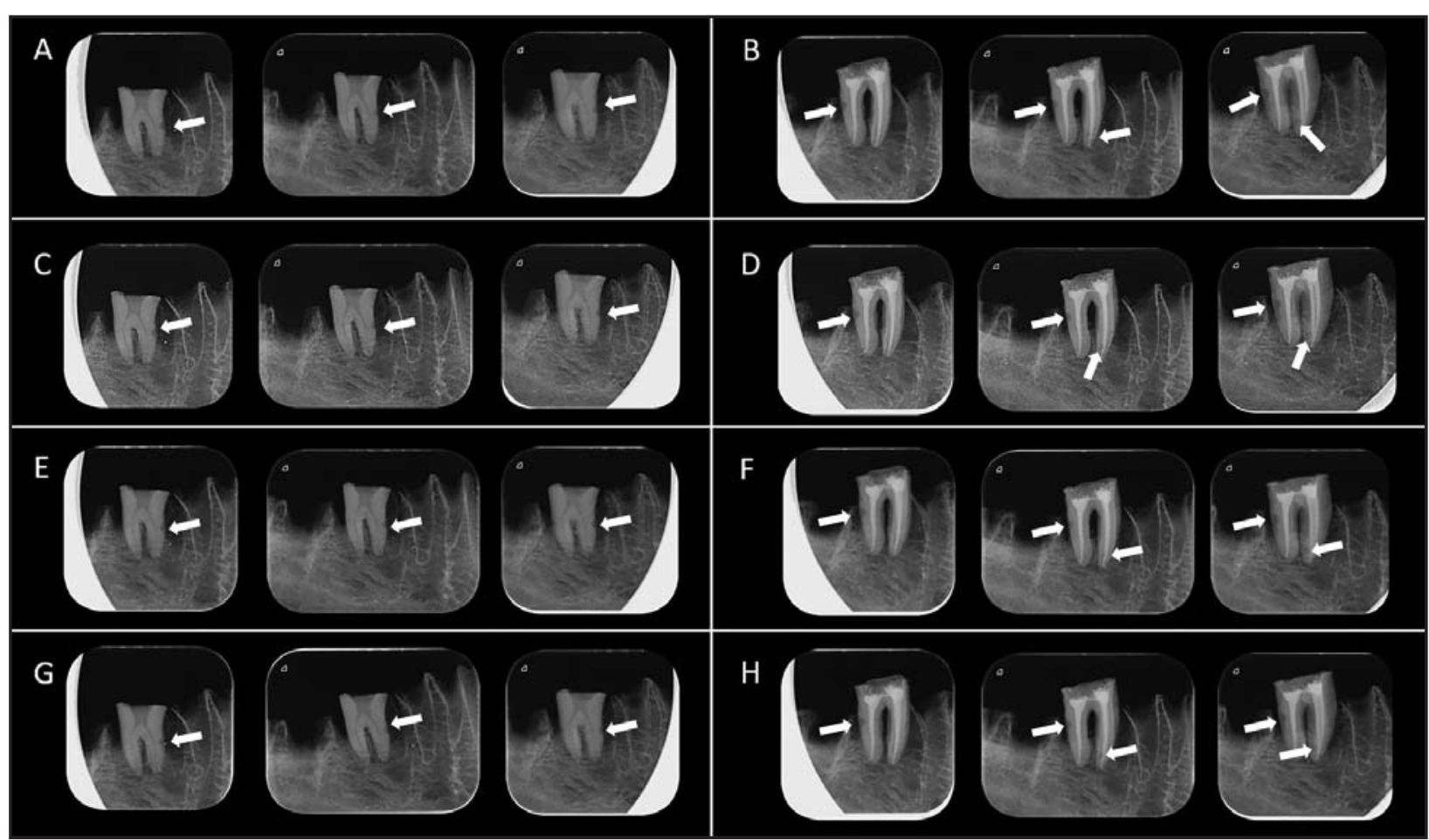

Fig. 1: Periapical radiographs of mandibular molars. (A) Absence of endodontic treatment and presence of simulated RRE in the middle third of the mesial root, $10 \mathrm{lp} / \mathrm{mm}$. (B) Presence of endodontic treatment and simulated RRE in the middle third of the distal root and in apical third of the mesial root, $10 \mathrm{lp} / \mathrm{mm}$. (C) and (D) - Spatial resolution $20 \mathrm{lp} / \mathrm{mm}$. (E) and (F) - Spatial resolution $25 \mathrm{lp} / \mathrm{mm}$. $(G)$ and $(H)$ - Spatial resolution $40 \mathrm{lp} / \mathrm{m}$ (white arrows). 
0.714 and 0.823 . For root-filled teeth, the values of sensitivity and accuracy at a resolution of $25 \mathrm{lp} / \mathrm{mm}$ were higher, 0.769 and 0.887 respectively, whereas no difference was found in specificity between different spatial resolutions (Table 1).

With regard to the extent of ERR, it was found that different types of spatial resolution produced different results $(P<0.001)$. For small ERRs, spatial resolution of $10 \mathrm{lp} / \mathrm{mm}$ was less accurate $(0.755)$ than that of $25 \mathrm{lp} / \mathrm{mm}(0.848)$. For moderate ERRs, on the other hand, accuracy was higher at a resolution of $40 \mathrm{lp} / \mathrm{mm}(0.885)$ than at other resolutions. Extensive ERRs were significantly better identified at a resolution of $25 \mathrm{lp} / \mathrm{mm}(0.891)$, whereas a resolution of $40 \mathrm{lp} / \mathrm{mm}$ enabled less accurate identification (0.876) (Table 2).

By correlating the percentage of diagnostic hits to localization of ERR at different spatial resolutions, it was possible to verify that the percentage of hits was lower in the cervical third than that in the other thirds for all resolutions tested, whereas ERRs located in the middle third were more easily detected (Table 3).

Table 1: Values of diagnostic tests for the different spatial resolutions, in the presence and absence of root filling.

\begin{tabular}{|c|c|c|c|c|c|c|}
\hline & \multicolumn{6}{|c|}{ Spatial Resolution } \\
\hline & & $10 \mathrm{lp} / \mathrm{mm}$ & $20 \mathrm{lp} / \mathrm{mm}$ & $25 \mathrm{lp} / \mathrm{mm}$ & $40 \mathrm{lp} / \mathrm{mm}$ & P Value \\
\hline \multirow[t]{2}{*}{ Sensitivity } & WORF & $0.889^{A, a}$ & $0.917^{\mathrm{B}, \mathrm{a}}$ & $0.806^{\mathrm{C}, \mathrm{a}}$ & $0.611^{\mathrm{D}, \mathrm{a}}$ & $P<0.001$ \\
\hline & WRF & $0.718^{\mathrm{A}, \mathrm{b}}$ & $0.744^{\mathrm{B}, \mathrm{b}}$ & $0.769^{c, b}$ & $0.744^{\mathrm{B}, \mathrm{b}}$ & $P<0.001$ \\
\hline \multirow[t]{2}{*}{ Specificity } & WORF & $0.714^{\mathrm{A}, \mathrm{a}}$ & $0.857^{\mathrm{B}, \mathrm{a}}$ & $0.786^{\mathrm{C}, \mathrm{a}}$ & $1.000^{\mathrm{D}, \mathrm{a}}$ & $P<0.001$ \\
\hline & WRF & $0.923^{\mathrm{A}, \mathrm{b}}$ & $0.923^{A, b}$ & $0.923^{A, b}$ & $0.923^{A, b}$ & $P=1.000$ \\
\hline \multirow[t]{2}{*}{$A Z$} & WORF & $0.823^{\mathrm{A}, \mathrm{a}}$ & $0.836^{\mathrm{B}, \mathrm{a}}$ & $0.832^{\mathrm{c}, \mathrm{a}}$ & $0.873^{\mathrm{D}, \mathrm{a}}$ & $P<0.001$ \\
\hline & WRF & $0.841^{A, b}$ & $0.848^{\mathrm{B}, \mathrm{b}}$ & $0.887^{\mathrm{c}, \mathrm{b}}$ & $0.864^{\mathrm{D}, \mathrm{b}}$ & $P<0.001$ \\
\hline
\end{tabular}

AZ, Area under the ROC curves. Lp/mm, line/pair per millimetre. WORF, Without root filling. WRF, With root filling.

For each diagnostic parameter value, different capital letters indicate significant difference $(P<.01)$ between the different spatial resolutions, in the WORF and WRF conditions.

For each diagnostic parameter value, different lowercase letters indicate significant difference $(P<.01)$ between the WORF and WRF conditions.

Table 2: $A Z$ values for the different sizes of simulated external root resorption in the different spatial resolutions.

\begin{tabular}{|c|c|c|c|c|c|}
\hline \multicolumn{6}{|c|}{ Spatial Resolution } \\
\hline Size of ERR & $10 \mathrm{lp} / \mathrm{mm}$ & $20 \mathrm{lp} / \mathrm{mm}$ & $25 \mathrm{lp} / \mathrm{mm}$ & $40 \mathrm{lp} / \mathrm{mm}$ & P Value \\
\hline Small ERR & $0.755^{\mathrm{A}}$ & $0.827^{\mathrm{B}}$ & $0.848^{C}$ & $0.831^{\mathrm{B}}$ & $P<0,001$ \\
\hline Medium ERR & $0.833^{A}$ & $0.829^{A}$ & $0.826^{A}$ & $0.885^{\mathrm{B}}$ & $P<0,001$ \\
\hline Extensive ERR & $0.876^{A}$ & $0.849^{\mathrm{B}}$ & $0.891^{c}$ & $0.847^{B}$ & $P<0,001$ \\
\hline
\end{tabular}

\section{Table 3: Relative frequency of correct diagnosis of the location of the simulated external root resorptions in the} different spatial resolutions.

\section{Spatial Resolution}

\begin{tabular}{|l|c|c|c|c|}
\hline Location of ERR & $\mathbf{1 0 ~ I p / m m}$ & $\mathbf{2 0 ~ I p / m m}$ & $\mathbf{2 5} \mathbf{I p / m m}$ & $\mathbf{4 0 ~ I p / m m}$ \\
\hline Absence of ERR & $88.90 \%$ & $92.60 \%$ & $85.20 \%$ & $88.90 \%$ \\
\hline Cervical third ERR & $45.80 \%$ & $41.70 \%$ & $45.80 \%$ & $41.70 \%$ \\
\hline Middle third ERR & $77.80 \%$ & $88.90 \%$ & $96.30 \%$ & $85.20 \%$ \\
\hline Apical third ERR & $45.80 \%$ & $50.00 \%$ & $50.00 \%$ & $58.00 \%$ \\
\hline
\end{tabular}




\section{DISCUSSION}

The aim of the present study was to ascertain whether spatial resolution (line pairs per millimetre) has any influence on the diagnosis of simulated ERRs in multi-rooted teeth by using digital periapical radiography.

The results show that both spatial resolution and different root canal conditions (i.e. root-filled or non-root-filled) had a significant influence on the detection of simulated ERRs on digital periapical radiographs.

Based on the diagnostic efficacy of spatial resolution for detection of simulated EERs on digital radiographs, high spatial resolutions were expected to have higher values of specificity, sensitivity and accuracy. For non-root-filled teeth, however, these expected results were found for specificity and accuracy as they were higher at a resolution of 40 $\mathrm{lp} / \mathrm{mm}$ and lower at $10 \mathrm{lp} / \mathrm{mm}$.

These findings corroborate the literature, showing that images acquired at high spatial resolutions enable better detection of radiographic details ${ }^{9,10,13,14}$. Nevertheless, contrary to our expectations, better results for accuracy were found for root-filled teeth at a resolution of $25 \mathrm{lp} / \mathrm{mm}$. This finding is important because it shows that it is possible to make a precise diagnosis without spending a long time on scanning, as occurs during the use of line pairs in high spatial resolution imaging. Another inherent advantage is small image file size, which also enables easy data export.

No statistical difference was observed for specificity in root-filled teeth. Although it is not feasible to perform a direct comparison due to methodological differences, a previous study corroborated our finding by demonstrating that different systems with different spatial resolutions showed no statistical difference in the detection of vertical root fracture ${ }^{15}$. On the other hand, analysis of sensitivity showed better results in non-root filled teeth at a resolution of $20 \mathrm{lp} / \mathrm{mm}$, whereas higher sensitivity was found in root-filled teeth at a resolution of $25 \mathrm{lp} / \mathrm{mm}$. For this reason, considering the diagnostic difficulties minimised due to the lack of filling material, the use of a lower resolution was enough for a precise diagnosis, whereas a higher resolution enabled safer diagnosis in teeth whose images were affected by the filling material.

These data are similar to those reported by a recent study assessing different intra-radicular conditions during the diagnosis process. Teeth filled with gutta-percha or restored with intra-radicular posts were more poorly diagnosed than those without root filling ${ }^{15,16}$.

With regard to the extent of ERRs, the present study has demonstrated that higher spatial resolutions improve accuracy in detecting small to moderatesized ERRs, although it has been suggested that the higher the spatial resolution, the better the identification of radiographic details ${ }^{17}$. Studies using different spatial resolutions were also performed to detect morphological alterations such as vertical root fractures ${ }^{9}$ and deep caries lesions ${ }^{18}$, reporting better results for higher resolutions, which corroborates our findings.

For extensive ERRs, accuracy was better at a resolution of $25 \mathrm{lp} / \mathrm{mm}$ and worse at $40 \mathrm{lp} / \mathrm{mm}$. This can be explained by the fact that an increase in spatial resolution without altering the exposure time, i.e., a proportionally longer exposure is needed for a higher spatial resolution in order to keep the same quality of the image acquired with lower spatial resolution ${ }^{17}$. Because extensive ERRs show a greater number of radiographic details and the study was performed with the same exposure time despite the different spatial resolutions, such details were more easily identified at lower resolutions.

In addition, greater wear of the root structure leads to a larger radiolucent area. Therefore, the accurate diagnosis of root resorption was higher for larger cavities $^{4}$. The same finding was reported by a study on ERR with different sizes, showing that extensive resorptions were not considered a diagnostic challenge as they could be easily identified in all modalities tested ${ }^{19}$.

With regard to the location of ERRs, middle third was the region enabling the most precise diagnosis, whereas the lowest percentage of diagnostic hits was observed in the cervical third for all spatial resolutions. Statistical differences between different root thirds have also been reported in the literature ${ }^{5,20}$, with the middle third enabling the best results ${ }^{5}$, which corroborates our study.

These findings can be attributed to a higher density and greater thickness of the structures superimposed in the cervical region, such as surrounding bone, root dentine and, in cases of root-filled teeth, greater amount of filling material.

On the other hand, a study using other digital methods with PSPs did not show any statistically 
significant superiority in detecting ERRs with different sizes and in different sites ${ }^{3}$.

The failure in timely diagnosis of ERR may lead to loss of dental structure and decrease the likelihood of preserving the tooth, since resorptive lesions are the first ones to be diagnosed on intra-oral radiographs. Safe radiographic techniques for diagnosis of such lesions is therefore necessary ${ }^{6}$.

Spatial resolution, usually expressed as line pairs per millimetre $(1 \mathrm{p} / \mathrm{mm})$, is a characteristic of digital receptors that enables differentiation of image details. To date, however, there is no study describing the effect of different spatial resolutions using a semidirect digital imaging system (phosphor storage plates) on the detection of ERR.

The present study used two-rooted lower molars with healthy roots. Multi-rooted teeth were selected because their morphology is largely affected by necessary endodontic procedures, thus posing a great challenge during the diagnosis of ERR due to root superimposition, which may result in poor therapeutic outcome. Different intra-radicular conditions (i.e. root-filled and non-root-filled teeth) were prepared in order to create diagnostic difficulties resulting from the filling material.

In the present study, teeth with simulated resorption cavities were considered to be the gold standard, which enabled the calculation of the exact percentage of positive and negative readings. It should be emphasised that simulated ERRs have relatively distinct cavity ridges, making them fairly easy to detect compared to naturally formed ERRs, which have more diffuse ridges ${ }^{6}$.

We also decided to simulate ERRs on the whole surface of the root and in three different regions to reproduce the likelihood of finding them in dental practice. Moreover, the teeth were placed within the alveoli of dried mandibles in order to better simulate the condition of their roots, i.e., surrounded by bone trabeculae and peripheral bone contour ${ }^{2}$. In addition, tissue attenuation and $\mathrm{x}$-ray dispersion were precisely simulated in the acrylic apparatus ${ }^{21}$.

To follow the ALARA principle (as low as reasonably achievable), exposure time was determined by means of a pilot study in which the image quality was obtained for all radiographs and maintained constant for all exposures, regardless of the spatial resolution. The aims of this procedure were to enable clinical reproducibility in terms of radiation exposure level and to ensure that any statistical differences were exclusively related to spatial changes.

Similarly, based on specific guidelines for radiologic diagnosis of tooth fractures ${ }^{22}$, in which at least two radiographs should be taken for diagnosis, the present work has extrapolated this recommendation by performing a radiographic triad for each tooth at different spatial resolutions in order to increase diagnostic sensitivity.

ERRs not viewed on orthoradial images were thus more likely to be detected after altering the horizontal angles ${ }^{23}$.

With regard to image evaluation criteria, it has been reported that subjective analysis of the image quality of a digital radiographic system is rather complex because it is directly related to sensitivity and dynamic scale of each examiner and related to the importance of the object of analysis ${ }^{8}$. In the present study, nevertheless, the examiners were previously trained and their analyses tested by means of a ROC curve. This approach enabled outlier data to be eliminated in order to increase the reliability of the study.

However, the present study has limitations inherent to the laboratory method and the results should be extrapolated to clinical practice with caution. In addition to the fact that simulated ERRs were relatively sharper than naturally formed ERRs, which tend to be rather diffuse and calcified, data on painful symptoms, crown colour and patient's dental history can help contextualise the observations made during interpretation of the images.

Therefore, further research should be carried out ex vivo by using a methodology similar to ours in order to precisely compare specificity, sensitivity and accuracy of digital imaging systems in the detection of ERR, as well as studies using irregular resorption cavities to better simulate clinical features. In conclusion, it has been found that spatial resolution influenced the detection of simulated ERRs on digital periapical radiographs, as well as their location, size, root canal configuration and presence of filling material. 


\section{Funding}

None

\section{CORRESPONDENCE}

Dr. Mariane FLS Lacerda

Av. Doutor Raimundo Rezende, 330, Centro, Sala 301, Governador Valadares,

Minas Gerais, Brasil. Zip Code: 35010-177

mariane.lopes.santos@gmail.com

\section{REFERENCES}

1. Vaz ASL, Vasconcelos TV, Neves FS, de Freitas DQ, HaiterNeto F. Influence of cone-beam computed tomography enhancement filters on diagnosis of simulated external root resorption. J Endod 2012; 38:305-308.

2. Creanga A, Geha H, Sankar V, Teixeira F. McMahan C, Noujeim M. Accuracy of digital periapical radiography and cone-beam computed tomography in detecting root resorption. Imaging Sci Dent 2015; 45:153-158.

3. Shokri A, Mortazavi H, Salemi F, Javadian A, Bakhtiari $H$, Matlabi H. Diagnosis of simulated external root resorption using conventional intraoral film radiography, CCD, PSP, and CBCT: a comparison study. Biomed J 2013; 36:18-22.

4. Mesgrani A, Haghanifar S, Ehsani M, Yaghub SD, Bijani A.Accuracy of conventional and digital radiography in detecting external root resorption. Iran Endod J 2014; 9:241-245.

5. Kamburoğlu K, Tsesis I, Kfir A, Kaffe I. Diagnosis of artificially induced external root resorption using conventional intraoral film radiography, CCD, and PSP: an ex vivo study. Oral Surg Oral Med Oral Pathol Oral Radiol Endod 2008; 106:885-891.

6. Sakhdari S,Khalilak Z,Najafi E,Cheraghi R. Diagnostic accuracy of charge-coupled device sensor and photostimulable phosphor plate receptor in the detection of external root resorption in vitro J Dent Res Dent Clin Dent Prospects 2015; 9:18-22.

7. Nejaim Y, Gomes AF, Silva EJ, Groppo FC, Neto H. The influence of number of line pairs in digital intra-oral radiography on the detection accuracy of horizontal root fractures. Dental Traumatol 2016; 32:180-184.

8. Bóscolo FN, Oliveira AEF, Almeida SM, Haiter CFS. Haiter N. A comparative clinical study of the image quality of the three digital radiographic systems, E-speed film and digital film. Pesqui Odontol Bras 2001; 15:327-333.

9. Wenzel A, Kirkevang LL. High resolution charge coupled device sensor vs. medium resolution photostimulable phosphor plate digital receptors for detection of root fractures in vitro. Dental Traumatol 2005; 21:32-36.

10. Li G, Berkhout WER, Sanderink GCH, Martins M. Stelt PF. Detection of in vitro proximal caries in storage phosphor plate radiographs scanned with different resolutions. Dentomaxillofac Radiol 2008; 37:325-329.

11. Ferreira LM, Visconti MAPG, Nascimento HA, Dallemolle RR, Ambrosano GM, Freitas DQ. Influence of CBCT enhancement filters on diagnosis of vertical root fractures: a simulation study in endodontically treated teeth with and without intracanal posts. Dentomaxillofac Radiol 2015; 44:1-6.

12. Landis JR, Koch GG. The measurement of observer agrement for categorical data. Biometrics 1977; 33:159-174.

13. Møystad A, Svanaes DB, Risnes S, Larheim TA. Gr€ondahl HG. Detection of approximal caries with a storage phosphor system. A comparison of enhanced digital images with dental X-ray film. Dentomaxillofac Radiol 1996; 25:202206.

14. Kositbowornchai S, Basiw M, Promwang Y, Moragorn H. Sooksuntisakoonchai N. Accuracy of diagnosing occlusal caries using enhanced digital images. Dentomaxillofac Radiol 2004; 33:236-240.

15. Nascimento HA, Neves FS, de-Azevedo-Vaz SL, Duque TM. Ambrosano GM, Freitas DQ. Impact of root filling and posts on the diagnostic ability of three intraoral digital radiographic systems in detecting vertical root fractures. Int Endod J 2014; 48:864-871.

16. Lima TF, Gamba TO, Zaia AA, Soares AJ. Evaluation of cone beam computed tomography and periapical radiography in the diagnosis of root resorption. Australian Dent J 2016; 61:425-431.

17. Lin LM, Rosenberg PA, Lin J. Do procedural errors cause endodontic treatment failure? J Am Dent Assoc 2005; 136: 187-193.

18. Janhom A, van Ginkel FC, van Amerongen JP, van der Stelt PF. Scanning resolution and the detection of approximal caries. Dentomaxillofac Radiol 2001; 30:166-171.

19. Patel S, Dawood A, Wilson R, Horner K.Mannocci F. The detection and management of root resorption lesions using intraoral radiography and cone beam computed tomography- an in vivo investigation. Int Endod J 2009; 42:831-838.

20. Andreasen FM, Sewerin I, Mandel U, Andreasen JO. Radiographic assessment of simulated root resorption cavities. Endod Dent Traumatol 1987; 3:21-27.

21. Durack C, Patel S, Davies J, Wilson R. Mannocci F. Diagnostic accuracy of small volume cone beam computed tomography and intraoral periapical radiography for the detection of simulated external inflammatory root resorption. Int Endod J 2011; 44:136-147.

22. Sonnabend $E$. The role of $x$-ray films in diagnosis in operative dentistry. Dtsch Zahnarztl Z 1990; 45:691-695.

23. Westphalen VP, Gomes de Moraes I, Westphalen FH, Martins WD. Souza PH.Conventional and digital radiographic methods in the detection of simulated external root resorptions: a comparative study. Dentomaxillofac Radiol 2004; 33:233-235. 